\title{
TRACER STUDY JURUSAN PENDIDIKAN IPS PEMETAAN DAN IDENTIFIKASI KETERSERAPAN DI DUNIA KERJA LULUSAN JURUSAN PENDIDIKAN ILMU PENGETAHUAN SOSIAL FAKULTAS ILMU SOSIAL UNIVERSITAS NEGERI YOGYAKARTA TAHUN 2014
}

\author{
Saliman, Satriyo Wibowo, Supardi \\ Pendidikan IPS Fakultas Ilmu Sosial UNY \\ Email: salimanjaper@uny.ac.id, Hp: 08122747937
}

\begin{abstract}
Abstrak
Penelitian ini bertujuan untuk mengidentifikasikan profil lulusan Jurusan Pendidikan IPS tahun 2008-2010 dan Relevansi kurikulum di Jurusan Pendidikan IPS UNY dengan kebutuhan pasar kerja. Profil lulusan meliputi masa tunggu lulusan, persen lulusan yang sudah bekerja, dan penghasilan pertama yang diperoleh. Metode penelitian Tracer Study ini dilakukan secara deskriptif dengan pendekatan survei. Subjek penelitian adalah lulusan Jurusan Pendidikan IPS FIS UNY tahun 2008-2010 sebanyak 51 orang. Hasil pengumpulan data dengan teknik angket dan dokumentasi diperoleh balikan sejumlah 47 orang. Teknik analisis data yang digunakan adalah analisis deskriptif dengan persentase kemudian dideskripsikan sebagai gambaran profil dari lulusan. Hasil penelitian diperoleh 1. Profil lulusan Jurusan Pendidikan IPS tahun 2008-2009 sebagai berikut: a. sebanyak 63,8 persen lulusan sudah memperoleh pekerjaan kurang dari enam bulan, 36,2 persen lulusan memperoleh pekerjaan pertama lebih dari 6 bulan, b. Persentase lulusan yang sudah bekerja sebagai Guru yaitu 60 persen dan non Guru 28,4 persen, serta hanya 11 , persen belum bekerja. c. Penghasilan pertama yang diperoleh sebanyak 52 persen kurang dari Rp 700.00,-, dan 47 persen lulusan antara $\mathrm{Rp} 751.000,00$ - Rp 1000.000,00. 2. Relevansi kurikulum dengan kebutuhan pasar kerja diperoleh hasil sebanyak 78,95 persen lulusan merasa memiliki life skill untuk jenis pekerjaan yang sesuai latar pendidikan dan 78,79 persen lulusan menyatakan materi kuliah yang diberikan di Jurusan Pendidikan IPS sudah sesuai kebutuhan pekerjaan yang sesuai latar belakang pendidikan.
\end{abstract}

Kata kunci: tracer study, relevansi, lulusan, IPS 


\section{Abstract}

This study aimed to identify the profile of graduates of 2008-2010 Department of Social Education and relevance of the curriculum in the Department of Social Education UNY with labor market needs. Profile graduates include graduates waiting period, the percent of graduates who are already working, and earning first obtained. Tracer Study Methods This study is a descriptive survey approach. Subjects were graduates of the Department of Social Education FIS UNY in 2008-2010 as many as 51 people. The data collected by questionnaire technique and documentation obtained by inverse number of 47 people. The data analysis technique used is descriptive analysis with percentages later described as a picture of the graduate profile. The results were obtained 1. Department of Social Education Graduate profile 2008-2009 as follows: a. as much as $63.8 \%$ of graduates have obtained employment for less than six months, $36.2 \%$ of graduates obtaining first job more than 6 months, $b$. The percentage of graduates who had worked as a teacher of $60 \%$ and $28.4 \%$ of non Guru, and only $11 \%$ have not worked. c. The first income earned as much as 52 $\%$ less than $R p$ 700.00,-, and $47 \%$ of graduates between $R p$ 751,000.00 USD 1000.000,00. 2. The relevance of the curriculum to the needs of the labor market as much as $78.95 \%$ obtained results graduates feel they have life skills appropriate to the type of work and the educational background of $78.79 \%$ of graduates stated lectures given at the Department of Social Education as required has the appropriate background job education.

Keywords: tracer studies, relevance, graduate, IPS

\section{Pendahuluan}

Pertanyaan yang sering muncul setelah seseorang menyelesaikan jenjang pendidikan tinggi ialah akan kerja apa, di mana, dan untuk siapa. Pertanyaan tersebut mengindikasikan perubahan kesadaran sekaligus harapan bahwa pengetahuan dan keterampilan yang diperoleh di bangku kuliah dapat bermanfaat bagi orang lain melalui karya nyata sang sarjana.

Demikian pula secara kelembagaan, lembaga pendidikan ditagih oleh stakeholders tentang kiprah nyata mencerdaskan generasi bangsa dalam wujud melahirkan lulusan yang berkualitas secara akademis maupun yang anggun kepribadiannya. Untuk melaksanakan cita-cita mulia 
tersebut, lembaga pendidikan dituntut untuk terus mereorganisasi dirinya dan meningkatkan kualitas layanan pendidikan kepada public. Salah satunya melalui penilaian kinerja program studi oleh Badan Akreditasi Nasional Perguruan Tinggi (BAN PT) dan penyusunan laporan Evaluasi Diri sebagai dasar pijakan konsolidasi organisasi dan pengembangan program kegiatan akademik. Salah satu butir evaluasi diri dan isian borang akreditasi ialah mengenai keberadaan lulusan setelah meninggalkan bangku kuliah.

Seberapa besar lulusan perguruan tinggi mampu berkiprah dalam pembangunan sesuai relevansi pendidikannya dapat dilakukan upaya penelusuran terhadap lulusannya (Tracer Study). Tracer Study merupakan pendekatan yang memungkinkan institusi pendidikan tinggi memperoleh informasi tentang kekurangan yang mungkin terjadi dalam proses pendidikan dan proses pembelajaran dan dapat merupakan dasar untuk perencanaan aktivitas untuk penyempurnaan di masa mendatang. Hasil Tracer Study dapat digunakan perguruan tinggi untuk mengetahui keberhasilan proses pendidikan yang telah dilakukan terhadap anak didiknya. Bahkan dalam program hibah kompetisi maupun akreditasi selalu mempersyaratkan adanya data hasil Tracer Study tersebut melalui parameter masa tunggu lulusan, persen lulusan yang sudah bekerja, dan penghasilan pertama yang diperoleh.

Harald Schomburg (2003: 11) mendefiniskan Tracer Study merupakan pendekatan yang memungkinkan institusi pendidikan tinggi memperoleh informasi tentang kekurangan yang mungkin terjadi dalam proses pendidikan dan proses pembelajaran dan dapat merupakan dasar untuk perencanaan aktivitas untuk penyempurnaan di masa mendatang. Informasi yang diberikan oleh lulusan yang berhasil di profesinya diperlukan misalnya informasi tentang pengetahuan dan penampilan yang relevan (hubungan antara pengetahuan terhadap ketrampilan dan tuntutan pekerjaan, area pekerjaan, posisi profesi). Selain itu, para 
lulusan dapat juga diminta.untuk menilai kondisi studi yang mereka alami selama mengikuti proses pendidikan dan pembelajaran. Tracer Study dapat juga digunakan sebagai kegiatan mencari informasi tentang kebutuhan stakeholder terhadap alumni. Tujuan dari kegiatan ini adalah mengumpulkan informasi dan masukan yang relevan dari lulusan terkait dengan "learning dan working experience" yang dialami oleh lulusan guna pengembangan Perguruan Tinggi. Menurut Schomburg (2003) tujuan utama dari kegiatan Tracer Study adalah untuk mengetahui/mengidentifikasi kualitas lulusan di dunia kerja, sedangkan tujuan khusus Tracer Study adalah : 1) Mengidentifikasi profil kompetensi dan keterampilan lulusan. 2) Mengetahui relevansi dari pelaksanaan kurikulum yang telah diterapkan di perguruan tinggi dengan kebutuhan pasar tenaga kerja dan pengembangan professional di dalam kompetensi jurusan. 3) Untuk mengevaluasi hubungan dari kurikulum dan studi di jurusan sebagai pengembangan keilmuan. 4) Sebagai kontribusi dalam proses akreditasi jurusan.

Jurusan Pendidikan IPS FIS UNY telah meluluskan 51 orang yang terbagi dalam 2 dua angkatan mahasiswa, semenjak mulai beroperasi pada tahun 2008 sampai dengan bulan Maret 2013. Namun keberadaan alumni setelah lulus belum dapat dipantau, baik mengenai masa tunggu lulusan sampai mendapatkan pekerjaan, kepuasaan stakeholders atas kinerja alumni, pengembangan wawasan kependidikan alumni, keterampilan keguruan alumni, maupun kepuasan alumni atas layanan pendidikan yang diberikan program studi selama mereka mengikuti pendidikan.

Adapun tujuan dari penelitian ini adalah untuk mengetahui : 1) Masa tunggu alumni sampai mendapatkan pekerjaan. 2) Relevansi antara kurikulum dengan kebutuhan di lapangan.

Manfaat yang diharapkan dari penelitian ini meliputi : 1) Bagi Program Studi, program studi dapat mengetahui jumlah alumni yang sudah 
bekerja sesuai dengan latar belakang pendidikan dan mengevaluasi relevansi kurikulum yang sudah ada untuk meningkatkan kualitas layanan Jurusan PIPS FIS UNY; 2) Bagi Mahasiswa/alumni, mahasiswa memperoleh layanan informasi lowongan pekerjaan dan dapat memberikan masukan pada program studi mengenai kurikulum dan proses pendidikan pada Jurusan PIPS FIS UNY.

\section{Visi, Misi, Tujuan, dan Sasaran serta Strategi Pencapaian}

Visi, misi, tujuan dan sasaran Prodi Pendidikan IPS disusun berdasarkan visi, misi, tujuan dan sasaran universitas, dan fakultas, melalui rapat prodi yang diselenggarakan secara khusus untuk keperluan tersebut. Visi, misi, tujuan dan sasaran Prodi IPS juga mengacu pada kebutuhan akan guru IPS di SMP/MTs dan SMK, yang menurut Kurikulum SMP dan SMK seharusnya diampu oleh guru dengan latar belakang pendidikan IPS.

Program Studi Pendidikan IPS merupakan Program Studi IPS pertama di Indonesia. Prodi PIPS telah memiliki ijin operasional sejak tahun 2007, tetapi baru mulai menerima mahasiswa baru tahun 2008. Sampai tahun ajaran 2010/2011, Prodi Pendidikan IPS memiliki 238 mahasiswa. Sejarah lahirnya Prodi Pendidikan IPS tidak lepas dari sejarah lahirnya Kurikulum tahun 2006, atau sering disebut Kurikulum Tingkat Satuan Pendidikan (KTSP) terutama di tingkat SMP. Sejak diberlakukanya kurikulum uji coba tahun 2004, mata pelajaran IPS menjadi mata pelajaran tunggal yang sebelumnya merupakan mata pelajaran Sejarah, IPS, dan Ekonomi.

Organisasi Himpunan Sarjana Pendidikan Ilmu-ilmu Sosial (HISPISI) juga berperan penting dalam kelahiran Prodi Pendidikan IPS. Melalui forum-forum seminar dan lokakarya yang diselenggarakan HISPISI, ide pendirian Prodi Pendidikan IPS untuk menyiapkan guru IPS SMP semakin mengkristal. Beberapa tokoh UNY yang berperan besar dalam kelahiran Prodi Pendidikan IPS misalnya Prof. Zamroni, Ph.D, 
Prof. Dr. Saidihardjo (alm), Dr. Muhsinatun Siasah M, Dr. Mukminan, dan Drs. Sardiman AM, M.Pd. Pada tahun 2006 Dekan FISE UNY menugaskan sebuah tim yang diketuai Sardiman AM untuk mengajukan proposal kepada Direktur Jenderal Pendidikan Tinggi tentang pendirian Prodi Pendidikan IPS. Proposal tersebut dikabulkan oleh DIKTI dengan dikeluarkannya Surat Ijin Operasional. Mulai tahun 2007, sebenarnya Prodi Pendidikan IPS telah memperoleh ijin menerima mahasiswa baru. Dengan berbagai pertimbangan, akhirnya baru tahun 2008 Prodi Pendidikan IPS menerima mahasiswa baru. Untuk kelancaran organisasi, Dekan FISE UNY mengangkat Saliman M.Pd. sebagai Ketua Ketua Prodi Pendidikan IPS.

\section{Visi Jurusan PIPS}

Mewujudkan program studi yang unggul dalam menciptakan tenaga kependidikan yang bertaqwa kepada Tuhan Yang Maha Esa, kompeten di bidang pendidikan Ilmu Pengetahuan Sosial, fleksibel, memiliki semangat kebangsaan, cinta tanah air, arif, kritis, demokratis, responsif terhadap berbagai masalah sosial dan tuntutan dunia global.

2. Misi Jurusan PIPS

a. Menyelenggarakan pendidikan akademik dalam bidang Pendidikan IPS untuk menjadi guru IPS SMP/MTs dan SMK yang bertaqwa Kepada Tuhan Yang Maha Esa, berkepribadian, menguasai ilmu pengetahuan dan teknologi, demokratis, berjiwa entrepreneurship dan responsif terhadap setiap peluang dan perubahan serta perkembangan yang terjadi.

b. Menumbuhkembangkan sikap dan kemampuan tenaga kependidikan untuk melakukan penelitian dalam rangka mengembangkan dan menyebarluaskan ilmu pengetahuan dan teknologi di bidang IPS. 
c. Menyelenggarakan pengabdian pada masyarakat dengan mendorong kemauan dan meningkatkan kemampuan tenaga kependidikan untuk mengamalkan ilmu pengetahuan dan ketrampilan, bagi kehidupan masyarakat baik di bidang pendidikan dan pengajaran, maupun bidang-bidang kehidupan sosial secara umum.

\section{Tujuan Jurusan PIPS}

a. Tujuan Umum

Membentuk manusia Indonesia seutuhnya yang berjiwa Pancasila, memiliki dedikasi, integritas, serta komitmen tinggi di dalam mengabdikan dirinya secara profesional untuk menunjang pembangunan nasional. Tujuan umum ini sejalan dengan tujuan pendidikan nasional seperti yang tertuang pada Undang-undang No. 20 Tahun 2003 tentang Pendidikan Nasional.

b. Tujuan Khusus

Menghasilkan pendidik yang memiliki kemampuan dalam:

1) Menjalankan kewajibannya sebagai sosok guru yang beriman dan bertaqwa kepada Tuhan Yang Maha Esa, berkepribadian, dan menjadi tauladan bagi peserta didik dan masyarakat.

2) Melaksanakan tugas sebagai guru IPS SMP/MTs dan atau SMK dalam arti menguasai materi ajar dan mampu mengelola pembelajaran yang bermakna di SMP/MTs dan atau SMK secara kritis, kreatif, dan inovatif.

3) Melakukan pekerjaan di luar bidang keguruan, seperti di bidang Pariwisata, Periklanan, Pers, dan sebagainya yang relevan dengan ilmu yang dipelajari. 
4) Mengembangkan keilmuan di bidang IPS untuk kepentingan pembelajaran, dan pembangunan lewat prosedur pendidikan dan atau penelitian yang relevan.

5) Melakukan antisipasi terhadap perubahan global sebagai akibat dari berkembangnya ilmu pengetahuan dan teknologi.

Sasaran Prodi Pendidikan IPS untuk meraih misi tersebut adalah :

1) Menciptakan suasana PBM yang berorientasi pada perkembangan bahan ajar yang mutakhir dan hasil-hasil penelitian dalam bidang sistem cerdas.

2) Evaluasi kurikulum yang relevan dengan perkembangan teknologi informasi.

3) Membentuk mahasiswa yang mampu berkompetisi dalam ajang kompetisi baik tingkat nasional maupun internasional.

4) Mencetak sarjana Pendidikan IPS yang mandiri dan mampu menerapkan kompetensinya terutama dalam bidang kependidikan

5) Menghasilkan sarjana PIPS yang kompetitif

Untuk mencapai tujuan dan sasaran maka strategi pencapaian yang dilakukan adalah:

1) Mengoptimalkan kinerja masing-masing bidang sesuai dengan tugas dan tanggungjawabnya.

2) Mengoptimalkan peran serta civitas akademika dan stake holder dalam merumuskan dan menyusun strategi pencapaian

3) Menerapkan system manajemen ISO yang telah dilakukan FIS UNY sejak tahun 2008

4) Pengembangan sumber daya manusia baik melalui studi lanjut maupun berbagai pelatihan

5) Pengambangan kurikulum yang menyesuaikan dengan perkembangan ipteks 
6) Pengembangan sistem pengelolaan proses belajar mengajar yang sistematis

7) Pengembangan sarana dan prasarana yang diperlukan untuk

8) Peningkatan serapan dan penggunaan biaya pelaksanaan pendidikan.

Alumni adalah kata benda jamak dalam bahasa Inggris yang berarti lulusan pria dari suatu sekolah. Bentuk tunggalnya adalah alumnus. Sedangkan alumna juga kata benda jamak dalam bahasa Inggris yang berarti lulusan wanita dari suatu sekolah. Bentuk tunggalnya adalah alumnae (John M. Echols dan Hasan Shadily, 1995:25-26). Dalam studi penulusuran ini akan menggunakan istilah bahasa Inggris yang sudah diserap ke dalam bahasa Indonesia, yaitu alumni tanpa membedakan jenis kelamin dari lulusan tersebut.

Penelusuran adalah kegiatan mencari informasi tentang hal yang belum diketahui dengan pasti. Informasi yang hendak digali dalam penelitian ini adalah tentang keberadaan alumni setelah meninggalkan bangku kuliah. Keberadaan alumni tersebut mencakup: (1) masa tunggu alumni semenjak lulus sampai dengan mendapatkan pekerjaan pertama, (2) tempat bekerja alumni, (3) perkembangan karir alumni, (4) cara alumni mengembangkan kemampuan akademik, (5) kepuasan stakeholders atas kinerja alumni, (6) kepuasan alumni atas kinerja program studi, (7) harapan stakeholders atas kinerja program studi, dan (8) harapan alumni atas kinerja program studi. 


\section{Kurikulum}

Kurikulum adalah seperangkat mata pelajaran yang diajarkan pada lembaga pendidikan atau seperangkat mata kuliah mengenai bidang keahlian khusus yang disajikan secara saling terkait satu sama lain (KBBI, 2002:617). Sampai saat ini belum ada kesatuan pendapat mengenai pengertian kurikulum. Pandangan lama menyatakan bahwa kurikulum merupakan seperangkat mata pelajaran dan materi pelajaran yang harus diajarkan oleh guru kepada peserta didik. (Moh. Ansyar dan Nurtain 1993). Sedangkan Oliver (dalam Brown dan Brown, 1985: 24) memberikan tiga macam definisi kurikulum yakni: (a) All the experiences a child as under the guidance of school, (b) all the courses or subject which the school offers, dan (c) the systematic arrangement of subject matter within a course offered by a school.

Said Hamid Hasan (1988) melihat kurikulum ada empat sudut pandang, yakni kurikulum sebagai ide, rencana tertulis, kegiatan dan hasil belajar. Sementara Hilda Taba berpendapat bahwa rumusan kurikulum yang terlalu luas justru akan mengaburkan pengertian kurikulum sendiri. Secara singkat, Hilda Taba (Nasution, 1993:10) merumuskan kurikulum "a plan" sebagai "forlearning" yakni sesuatu yang direncanakan untuk dipelajari oleh siswa.

Pengertian kurikulum dalam Undang-Undang No 20 Tahun 2003 tentang Sistem Pendidikan Nasional menyatakan bahwa kurikulum merupakan seperangkat dan pengaturan mengenai isi, tujuan dan bahan pelajaran serta cara yang digunakan sebagai pedoman penyelenggaraan kegiatan pembelajaran untuk mencapai tujuan pendidikan tertentu. 


\section{Metode Penelitian}

Jenis penelitian yang digunakan adalah penelitian sensus. Penelitian sensus adalah penelitian atas keseluruhan subjek penelitian atau populasi (Suharsimi Arikunto, 1996:115). Berdasarkan tujuan yang akan dicapai maka penelitian ini merupakan jenis penelitian deskreptif, yaitu suatu penelitian yang menguraikan sifat-sifat atau fenomena tertentu (umar, 1999:36). Penelitian ini bermaksud untuk menguraikan kondisi dan situasi dari alumni Jurusan Pendidikan Ilmu Pengetahuan Sosial FIS UNY yang terkait dengan aspek masa tunggu dan keterserapan alumni dalam duni kerja.

Penelitian dilaksanakan pada rentang waktu Mei sampai September 2014, dengan tempat utama di Universitas Negeri Yogyakarta.

\section{Langkah-langkah Penelitian}

1. Tahap Pra-lapangan

Pada tahap ini peneliti mengadakan survey pendahuluan. Selama proses ini peneliti mengadakan penjajagan lapangan (field study) terhadap subyek penelitian dan menyusun rancangan penelitian.

2. Tahap Pekerjaan Lapangan

Dalam tahap ini peneliti memasuki dan memahami setting penelitian dalam rangka pengumpulan data. Langkah-langkahnya adalah sebagai berikut:

a. Membuat rute penelusuran berdasarkan sebaran daerah asal alumni.

b. Melaksanakan penelusuran terhadap alumni yang terpilih secara acak dan lulus sampling.

c. Kuisioner diberikan kepada alumni.

d. Menyusun data lapangan sebagai bahan laporan.

e. Evaluasi dan refleksi.

3. Tahap Analisis Data

Peneliti melakukan serangkaian proses analisa data kuantitatif 
berupa angket sampai pada interpretasi data yang sudah diperoleh sebelumnya.

4. Tahap Evaluasi dan Pelaporan

Tahap ini merupakan tahap terakhir dan dilaksanakan setelah penelitian diuji.

Populasi penelitian ini adalah seluruh lulusan Jurusan Pendidikan IPS tahun masuk 2008 s/d 2010 yang telah menyelesaikan pendidikanya hingga bulan September 2014.

Berkaitan dengan sumber data penelitian maka pengambilan data pada penelitian ini menggunakan teknik survey dengan meyebarkan kuesioner kepada populasi.

Teknik analisis data yang dipergunakan dalam penelitian ini adalah sebagai berikut:

1. Reduksi data (Data Reduction), Proses ini dilaksanakan dengan memilah data dari catatan tertulis di lapangan.

2. Penyajian data (Display Data),

Data yang telah direduksi, disajikan dalam laporan sistematis, mudah dibaca dan difahami, baik secara keseluruhan maupun per bagian,

3. Pengambilan Kesimpulan (Verification)

Data yang telah diproses kemudian ditarik kesimpulan dengan menggunakan metode induktif, yaitu proses penyimpulan dari halhal yang sifatnya khusus ke hal-hal yang sifatnya umum agar diperoleh kesimpulan yang obyektif. 
JIPSINDO No. 1, Volume 2, Maret 2015

\section{Hasil Penelitian}

\section{Profil lulusan Jurusan Pendidikan IPS}

Berdasarkan hasil analisis dari angket yang peneliti sampaikan kepada alumni, maka alumni Jurusan Pendidikan IPS dapat digambarkan sebagai berikut: Usia alumni angkatan 2008 dan 2010 saat penelitian ini dilakasanakan berada dalam rentangan 23-25. Rata-rata usia alumni adalah 23,6 tahun. Jenis kelamin alumni 37 \% diantaranya adalah laki-laki, dan terdapat $63 \%$ perempuan. Untuk status pernikahan dari alumni baru ada 4,25\% yang sudah menikah, dan sisanya sebanyak 95,75 \% belum menikah.

Seluruh alumni tidak pernah mengambil cuti kuliah selama studi, dengan masa studi rata-rata dari mereka adalah 4,7 tahun. Terdapat 63,8 persen alumni sudah bekerja di berbagai sektor pekerjaan, 10,6 persen langsung melanjutkan studi S2 dan sisanya masih menganggur yaitu sebanyak 25,6 persen.

Masa tunggu alumni sampai mendapatkan pekerjaan pertama yaitu 0-3 bulan 21,3 \%, 4-6 bulan ada sebanyak 78,7 \%.

Masa transisi merupakan jeda waktu tunggu alumni dari lulus sampai mendapatkan pekerjaan pertamanya. Dalam masa tunggu ini alumni melakukan beberapa aktivitas yang meliputi:

a. Membuat surat lamaran

b. Mengikuti kursus/tambahan keahlian lainnya

c. Membuka usaha sendiri, menjadi tenaga serabutan, melanjutkan studi S2, menjadi tanaga les privat.

d. Bekerja serabutan kepada orang lain

Aktivitas yang di lakukan pada masa transisi ini, 43,7\% alumni tidak menggunakan bidang ilmu yang mereka pelajari di bangku kuliah dan 56,3 \% yang menyatakan dirinya beraktivitas sesuai dengan bidang keilmuan yang mereka pelajari di perkuliahan.

Bagi alumni yang belum bekerja pada saat pengisian angket penelusuran alumni ini, mereka memiliki beberapa alasan, yaitu:

a. Menunggu panggilan kerja dari bidang yang dilamar

b. Belum siap bekerja 
c. Sedang menempuh studi lanjut

d. Belum menemukan pekerjaan yang cocok

e. Menunggu tahun ajaran baru untuk mengajar di sekolah

Berdasarkan masukan dari alumni mengenai bekal keilmuan yang dapat mendukung cepatnya alumni dalam mendapatkan pekerjaan adalah sebagai berikut:

a. Keterampilan komputer dan kewirausahaan

b. Bahasa inggris

c. Informasi lowongan kerja, bursa kerja dan jaringan peluang kerja

d. Komunikasi dan kepenulisan

e. Penguatan microteaching dan PPL

f. Pengembangan kepribadian

g. Latihan psikotes

h. Keahlian pembuatan media pembelajaran

i. Semua sudah didapat saat kuliah

Kondisi kerja sangat penting untuk di telusuri karena erat kaitanya dengan kenyamanan kerja yang akan mereka jalani, kondisi kerja ini juga sangat mempengaruhi keputusan alumni dalam memimilih dan mentukan pekerjaanya baik jenis pekerjaanya, jauh tidaknya dengan tempat tinggal asli dari alumni, tidak sedikit dari alumni yaitu sebanyak 87,23 \% yang masih menginginkan pekerjaan yang dekat dengan tempat tinggalnya, kesesuaian latar belakang keahlian yang dimiliki sampai pada besaran gaji yang akan diterim alumni ketika bekerja.

Dari hasil penelusuran informasi pekerjaan didapatkan oleh para alumni dari berbagai saluran yaitu:
a. Melalui kenalan
b. Surat kabar
c. Internet
d. Radio
e. Usaha sendiri
f. Melalui informasi dari jurusan
g. Melalui pengumuman di kampus 
Lembaga tempat alumni bekerja dapat dikategorikan menjadi tiga jenis yaitu pemerintah, swasta dan usaha sendiri. Alumni yang bekerja di instansi pemerintah belum ada tetapi terdapat 5,6 \% yang mengikuti program khusus sebagai guru didaerah terluar Indonesia, yang bekerja di lembaga swasta sebanyak 15,6 \% dan yang bekerja dengan usaha sendiri sabanyak $4,8 \%$.

Sebaran bidang pekerjaan alumni tersebar ke berbagai bidang meliputi bidang pendidikan, industri, jasa dan lainya dengan rincian sebagai berikut:
a. Bidang pendidikan
b. Bidang industri
c. Bidang jasa
d. Lainya, yang meliputi perdagangan, serabutan, les privat

Alumni yang bekerja dalam bidang pendidikan tersebar kedalam beberapa jenjang pendidikan sebagai berikut:
a.PAUD-TK
b.SD
c. SMP

Besaran gaji yang diterima oleh alumni dalam pekerjaan pertamanya beragam mulai dari > RP 300.000,00 sampai > Rp 1000.000,00. Alumni yang mendapatkan gaji di bawah $\mathrm{Rp}$ 1000.000,00 perbulan dalam pekerjaan pertamnya sebanyak 81,68 persen, dan yang mendapatkan gajinya lebih dari Rp 1000.000,00 ada sebanyak 8,32 persen. Berkaitan dengan kesesuaian mata kuliah yang telah mereka pelajari selama studi di Jurusan Pendidika IPS dengan bidang pekerjaan yang mereka geluti terdapat $22 \%$ dari mereka menyatakan sangat sesuai, yang menyatakan sesuai sebanyak $43 \%, 27,7 \%$ alumni menyatakan tidak sesuai dan terdapat 7,3\% alumni yang menyatakan sangat tidak sesuai dengan pekerjaan yang sekarang mereka geluti.

Identifikasi kondisi tempat kerja alumni dimaksudkan untuk mengetahui mobilitas perubahan tempat kerja. Dinamika 
perkembangan dunia kerja saat ini berjalan dengan cepat mengikuti perkembangan jaman yang terjadi, kondisi ini menuntut almuni harus menyesuaikan diri dengan kebutuhan dari perubahan tersebut. Jenjang karir yang penuh dengan persaingan memerlukan alumni untuk terus mengembangkan diri untuk promosi kenaikan jabatan atau posisi.

Menghadapi situasi diatas $76 \%$ alumni yang sudah bekerja menyatakan bahwa mereka membutuhkan pengetahuan untuk peningkatan karir, namun masih terdapat $24 \%$ alumni yang tidak mengingikan pentingnya promosi jabatan. Adapun tambahan pengetahuan yang diperlukan adalah:

a. Metode pembelajaran

b. Enterpreneurship

c. Manajemen pendidikan

d. Pendidikan profesi guru

e. Marketing

f. Administrasi pembelajaran

g. Penguasaan bahasa asing

h. Keterampilan komputer dan multi media

i. Riset pendidikan

j. Jurnal penelitian

k. Akuntasi

1. Manajemen keuangan

m. Dasar-dasar ekonomi

n. Manajemen konflik

o. Penulisan karya ilmiah

Hambatan karir diarasakan oleh $31 \%$ alumni yang dikarenakan ketidak sesuaian mereka dalam dunia kerja yang sekarang mereka geluti tidak sebidang dengan bidang keahliah yang mereka pelajari di perkuliahan, tetapi terdapat $69 \%$ dari mereka yang menyatakan tidak ada hambatan walaupun perkerjaan sekarang tidak sesuai dengan bidang keahlian yang dulu di pelajari. 


\section{Simpulan}

1. Profil lulusan lulusan jurusan pendidikan IPS mempunyai masa tunggu lulusan sebagian besar kurang dari delapan bulan, Sebagian besar lulusan sudah bekerja sesuai latar belakang Pendidikan dengan penghasilan pertama yang diperoleh lulusan sebagian besar kurang dari satu juta rupiah sebagai guru. Atas dasar kondisi profil lulusan tersebut diketahui bahwa lulusan yang dihasilkan Jurusan Pendidikan IPS sudah sesuai dengan visi dan misi jurdik IPS

2. Relevansi kurikulum Jurusan Pendidikan IPS terhadap kebutuhan pasar kerja yaitu sebagian besar lulusan merasa memiliki life skill yang sesuai dengan jenis pekerjaan sebagai guru dan sebagian besar lulusan juga menyatakan materi yang diterima selama kuliah di Jurusan Pendidikan IPS sudah sesuai kebutuhan pekerjaan sebagai guru.

\section{Saran}

Berdasarkan kesimpulan yang diperoleh, maka disarankan bagi Jurusan Pendidikan IPS khususnya agar:

1. Memperjuangkan lulusan agar dapat memperoleh kesempatan memperoleh penghasilan pertama sebagai guru lebih dari satu juta rupiah, atau di atas Upah minimum daerah melalui forumforum terkait secara nasional.

2. Kekurangan-kekurangan yang dirasakan oleh lulusan yang dinyatakan dalam usulan mata kuliah maupun usulan perbaikan/penyempurnaan jurusan dapat ditindak lanjuti melalui peninjauan ulang terhadap mata kuliah yang diselenggarakan saat ini dan mengadakan Pelatihan/workshop bagi guru-guru IPS terutama lulusan Jurdik IPS UNY tentang penguasaan teknik pembelajaran dan materi pembelajaran terbaru seperti dalam forum pertemuan-pertemuan MGMP. 


\section{Daftar Pustaka}

Hanna Djumhana Bastaman. 1996. Meraih Hidup Bermakna: Kisah Pribadi dengan Pengalaman Tragis. Jakarta: Paramadina. Cetakan 1.

Hasan Alwi (dkk.). 2002. Kamus Besar Bahasa Indonesia. Jakarta: Balai Pustaka. Edisi Ketiga.

John M. Echols \& Hasan Shadily. 1995. Kamus Inggris -Indonesia: An English - Indonesian Dictionary. Jakarta Gramedia. Cetakan 21.

Masri Singarimbun \& Sofian Effendi (ed.). 1995. Metode Penelitian Survai. Jakarta: LP3ES. Cetakan 2.

Sudarwan Danim. 2002. Menjadi Peneliti Kualitatif. Bandung. Cet- 1.

Suharsimi Arikunto, 1996. Prosedur Penelitian Suatu Pendekatan Praktek. Jakarta: PT Rineka Cipta.

TIM Pengisi Borang. 2010, Borang Akreditasi Prodi PIPS. Yogyakarta: FIS UNY. Tidak diterbitkan. 